\title{
PREDICTION MODEL OF SUCCESS OR FAILURE FOR SMALL BUSINESS IN NORTH EAST INDIA
}

\author{
Dr. Bimal Deb Nath \\ Assistant Professor, Dept. of Management, NEHU Tura Campus, Meghalaya, India \\ Sugata Deb Nath \\ Research Scholar, Dept. of Management, NEHU Tura Campus, Meghalaya, India
}

\begin{abstract}
The aim of this study is to examine the factors that lead to success or failure of small business in North East India. This study methodology is a survey research testing the SMEs of North East India regarding business success and failure with a sample of 50 small businesses (25 failed and 25 successful) to better understand the reasons of their success or failure using logistic regression statistical analysis. The model will also predict a new small firm will be successful or failure in future.
\end{abstract}

Keyword: Entrepreneur, Small Business, Lussier Model, North East India, SME

Cite this Article: Dr. Bimal Deb Nath and Sugata Deb Nath, Prediction Model of Success or Failure for Small Business in North East India. Journal of Management, 6(1), 2019, pp. 197-201.

http://www.iaeme.com/jom/issues.asp?JType=JOM\&VType=6\&IType=1

\section{INTRODUCTION}

Small and Medium Enterprises (SMEs) constitute a large share of enterprises in most countries and are cornerstone of economies. They are major source of employment and income in most countries. However, they need to be competitive to survive and grow in the present era of liberalized and digital economy, making national boundaries almost irrelevant. Most of the SMEs are inward looking and not very competitive. They merely survive and sooner than later, seize to exist. One of the reasons for this lackluster performance is their inability to access and analyze right kind of information for decision making. Large corporates can afford to hire world class consultancy firms like McKinsey, Price Waterhouse Coopers, etc. whereas MSMEs find it almost impossible to afford them. These large firms get extra advantage, as the information generated by analysis of data collected using reliable research methodology, accurately serves the purpose of aiding them in making decisions under intricate situations. Also, data related to visitors of social media sites and navigation patterns on portals are widely used by large firms for predictive analysis. On the other hand, decision making at MSMEs is often based on ad-hoc methods or gut feeling making them more vulnerable to failures. Although, globalization has 
led to increased competition, it also offers opportunities for expansion of business, for firms with strategic and competitive strengths. Furthermore, the size of firm does not matter. In this era of digital economy, business success is strongly associated with up-to-date information and knowledge of markets, consumers and competitors acquired using scientifically proven research methods. Business research is vital for sustainability of SMEs in global economy. To grab opportunities that globalization offers, MSMEs need information to support their decisions on target markets, product-mix, branding, consumer perception, trends, supply and demand forecasting and quality control.

The Indian economy presents a significant opportunity for SMEs to achieve double digit business growth over the next decade. The policy reforms, infrastructure and defence spends, significant higher FDI numbers, 'Make in India' initiative and many more catalysts shall provide growth opportunities to small and medium businesses in India. In order to seize these opportunities, India's SME businesses have to transform and adopt the emerging trends in technology. This requires a careful understanding by SME promoters and their key management teams of what these technology trends are and how they can add value to their business model, operations and to all the stakeholders of the business, whether internal or external. With new advances in technology and various procurement and deployment options, investments in technology shall further become more affordable, justifying its ROI and business case.

India's North East Region (NER) has been acknowledged as the 'Eastern Gateway' for the Governments 'Look East Policy'.It is home to more than 45 million people (3.76 percent of India's population )with high literacy level (most North Eastern states being above the national average of 74.04 per cent). The region has recorded annual economic growth rate in excess of entrepreneurial activity?The North Eastern States collectively have have nearly 2 lakh MSMEs, which account for less than 2 per cent of the country's total MSMEs, according to the International Finance Corporation report. These industrial units face constraints in the form of land acquisition, availability of power, transport, logistics, credit disbursal, skilled labour, adequate marketing initiatives and issues in taxation. Unless these structural issues are addressed by the government, North East may not be able to sustain the robust growth in coming years. The challenges of SMEs in North East India have flowed mainly from their scale of operation, technological obsolescence, and inability to access institutional credit and intense competition in marketing.

On the greener side, economic growth in NER in the recent years has been impressive with 2.39 per cent contribution towards India's total GDP in 2011-12. A significant expansion in services sector has helped in the sustenance of such a high growth. In the absence of large-scale industries, manufacturing in North East is currently dominated by SMEs. Endowed with huge untapped natural resources (tea gardens, crude oil, natural gas, silk, bamboo, etc.), NER has got the potential to transform itself into a commercial hub of India and tourist paradise. Hence, it is necessary to mobilize the SMEs in North East to channelize their resources for economic development of the region. The present Study is an attempt to highlight various significant factors responsible for success or failure of SME in the present competitive business environment.

\section{LITERATURE REVIEW}

The section initially highlights various literature on the need for successful SME in North East India and finally explores various theoretical framework of the success and failure prediction model. 


\subsection{Need for successful SME in North East India}

The competitive nature of business requires that organizations, especially SMEs (Small and Medium Enterprises), develop and sustain any possible competitive advantage. Increasingly this requires that the tools of Information Technology not just enable electronic transactions to occur, but also to transform internal systems and help build relationships with customers. It helps the business by reducing costs, growing market prospective, and providing newer trade opportunities (Beck, Wigand, \& Konig, 2005; Fink \& Disterer, 2006; Grandon \& Pearson, 2004). SMEs have seen a drastic change in its business environment. It also offers the creation of opportunities for new businesses (Saxena et.al. 2014).

There is a need of more successful SMEs to nurture economies and less failure rate among these enterprises to avoid wasting valuable resources (Brustbauer, 2016; Hyder, Lussier, 2016). To minimize wastage of resources and the risk of failure of SMEs, various factors affecting success or failure (S/F) of SMEs have been identified (Pompe and Bilderbeek, 2005). Despite all the research carried out to date, failure rate of SMEs is high. In the USA for example, only half to a third of new enterprises survive beyond 5-10 years (SBA, 2017). The importance of SMEs to economic growth has long been recognized but the causes of what influence their success or failure is not. There is no doubt that understanding why some SMEs fail would lead to more successful and survival of more SMEs. In today's uncertain environment and the frenzied business competition the world is filled with stories of small businesses failing, that's why the cause of SMEs success and failure is a topic that has come under increased scrutiny, and although the history of the subject is rich in information and knowledge the reasons of failure remain an elusive matter (Olaison and Sørensen, 2014). With the absence of specific theory to identify the factors leading to SMEs success (Lussier and Halabi, 2010), there is a need to test SMEs success and failure models in multiple countries to validate results in different contexts (Bono and McNamar, 2011). Thereafter, the aim of this study is to identify the significant factors responsible for success and failure of SME where no similar previous study was carried out. On a global scale, North East India represents not only a different location on India but also differs from others by size, age, economy, political situation in the globe to date where SME are required to operate in extremely challenging situations.

\subsection{Theoretical framework of the success and failure prediction model}

Several researchers (Carter and Van Auken, 2006) have conducted study on several model regarding success and failure of SMEs. However, Lussier (1995) model was found to be more popular. Lussier is the most extensive model because the study examined the efficacy of 15 variables identified from 20 prior studies. The Lussier (1995) model identified fifteen variables in the literature and they are 1) working capital(wc); 2) record keeping and financial control(re); 3) industry experience(ie);4) management experience(me); 5) planning(plan); 6) professional advice(pa); 7) formal education (fe);8) staffing(staff); 9) product service timing(pst) ; 10) economic activity(ea); 11) age; 12) partners; 13) parents; 14) minority(minority); 15) marketing efforts (me) and therefore the study used these variables to predict success and failure of SME in North East India.

\section{METHODOLOGY}

The primary methodology of this study was survey research with data collected through structure questionnaire based on identified 15 variables and responses for each variable are measured in likert scale from 1 to 5 ( 1 -for strongly disagree to 5 -strongly agree) The study sample frame utilized two list of participants, one for successful and the other failure firms, with a sample unit of individual small business enterprises and the respondents are top level manager of the enterprise. All total 30 nos successful SMES and 30 nos Unsuccessful SMEs 
are selected from North East India for the study. The list was obtained from the respective MSME regional office and purposive sampling method consideration time limitation of the researcher. Of the 60 , 50 filled questionnaires were received for an 83 percent response rate;

\section{RESULTS AND DISCUSSION}

Based on the responses on the identified variables "mydata.csv" dataset is prepared in excel and

The logistic regression model in $\mathrm{R}$ software as follows :

Mylogit $=g l m\left(s \_f \sim w c+r k e+m e+p l a n+p a+f e+\right.$ staffing + pst+ea+age + parters + parents + minori ty + me, data $=$ mydata, family $=$ "binomial")

Where

$\mathrm{s} \_\mathrm{f}=$ success and failure of sme

$\mathrm{wc}=$ working capital ;

$\mathrm{re}=$ record keeping and financial control

$\mathrm{ie}=$ industry experience $(\mathrm{ie})$;

me $=$ management experience

plan= planning

$\mathrm{pa}=$ professional advice

$\mathrm{fa}=$ formal education

staff=staffing

pst $=$ product service timing

ea $=$ economic activity

me $=$ marketing efforts

mydata $=$ dataset of the study

With this model success and failure of the new SME may also be predicted with the following equation.

Newsme_sucess_failure $=$ predict $($ mylogit, newdata $=$ newdata, type $=$ "response")

Where

Newsme_sucess_failure $=$ to predict success and failure of new sme

Mylogit $=$ model designed

Newdata $=$ newdata of the sme

The results indicated that the successful firms had higher level measures of ten of the variables, which supports the probability of success of small businesses will increase if they have adequate capital, keep good records and financial control, have industry experience, have management experience, have specific business plans, receive professional advice, have higher level of education, have good product/service timing, have marketing skills, and are older in age. Thus, new SMEs in the North East India should make sure that they have the needed capital realistically calculated based on a specific business plan ensuring sales forecast and cash flow to keep the firm operational; good record keeping and financial control; and the business performance will be improved through seeking professional advice. 


\section{REFERENCES}

[1] Beck, R., Wigand, R. T., \& König, W, Integration of E-Commerce by SMEs in the Manufacturing Sector: A Data Envelopment Analysis Approach. Journal of Global Information Management, 13(3), 2005, pp 20 - 32.

[2] Bono, J.E. and McNamar, G, "From the editors", Academy of Management Journal, Vol. 54 No. 4, 2011, pp. 657-660.

[3] Brustbauer, J, "Enterprise risk management in SMEs: Towards a structural model", International Small Business Journal, Vol.34 No1, 2016, pp 70-85.

[4] Carter, R. and Van Auken, H, "Small firm bankruptcy", Journal of Small Business Management, Vol. 44 No. 4, 2006, pp. 493-512.

[5] Fink, D., \& Disterer, G, International case studies: To what extent is ICT infused into the operations of SMEs? Journal of Enterprise Information Management, 19(6), 2006, pp 608624.

[6] Grandon, E. E., \& Pearson, J. M, Electronic commerce adoption: an empirical study of small and medium US businesses. Information \& Management, 42(1), 2004, pp 197-216.

[7] Hyder, S., and Lussier, R. N, " Why businesses succeed or fail: a study on small businesses in Pakistan", Journal of Entrepreneurship in Emerging Economies, Vol.8 No. 1, 2016, pp $82-100$.

[8] Lussier, R,"A nonfinancial business success versus failure prediction model for young firms", Journal of Small Business Management, Vol.33 No. 1, 1995, pp. 8-20.

[9] Lussier, R. and Halabi, C. (2010)," A three-country comparison of the business success versus failure prediction model", Journal of Small Business Management, Vol.48 No. 3, 2010, pp. 360-377. http://dx.doi.org/10.1111/j.1540-627X.2010.00298.x

[10] Olaison, L., and Sørensen, B. M, "The abject of entrepreneurship: failure, fiasco, fraud", International Journal of Entrepreneurial Behaviour and Research, Vol.20 No.2, 2014, pp. 193-211.

[11] Pompe, P.M. and Bilderbeek, S, "The prediction of bankruptcy of small-and-medium sized industrial firms", Journal of Business Venturing, Vol. 20 No. 6, 2005, pp. 847-869.

[12] Saxena, S., Asthana, R \& Singh, D, A Review of Electronic Commerce Adoption Barriers in Small and Medium Enterprises (SMEs) in India. 11 th IRF International Conference, 15th June-2014, Pune, India, ISBN: 978-93-84209-27-8, 2014 